\title{
ECONOMIC ASPECTS OF THE DEVELOPMENT OF INSURANCE ACTIVITY OF SMALL BUSINESSES
}

\author{
Larysa Poliatykina ${ }^{1}$, Iryna Samoshkina ${ }^{2}$, Olena Slavkova ${ }^{3}$
}

\begin{abstract}
The goal of the article is to summarize and highlight the main economic aspects of the development of insurance activities of small businesses in the countries of Eastern Europe. The small business performs a number of important economic and social tasks. The main arguments in favour of the features of the organization and operation of insurance activities of small businesses are considered. The purpose of the research. The purpose of this scientific research is to develop a methodological approach to the organization of insurance activities in small business and make proposals on the ways of their improvement. Insurance provides reliable protection of property interests of entrepreneurs and the population in case of losses caused by fire, natural disaster, technogenic accidents, traffic accidents, and many other unforeseen circumstances. Problem statement. In the economy of countries of Eastern Europe, there are a number of features of small business development. Entrepreneurship contributes to the expansion of the sector of employment, the creation of new employment opportunities for the unemployed population, and the dismissal of employees from enterprises, which operate inefficiently. Insurance provides reliable protection of property interests of entrepreneurs and the population in case of losses caused by fire, natural disaster, technogenic accidents, traffic accidents, and many other unforeseen circumstances. Insurance has proved itself as a form of accumulation of funds of citizens to solve their social problems (health, pensions, education, etc.). In recent years, insurance is widely used in the event of third-party liability. The issue on the problems of the organization of insurance activities of small businesses has been and is studied in detail in periodicals and special literature. Methodology. The analysis of the operation of small business and the features of its conduct was made during the study. The issues of the formation and operation of small business, as well as workflow management and business administration at these enterprises, are controversial. As a result of the research, the regulatory framework of the operation of insurance enterprises in the sphere of small business has been analysed. The article focuses on the main arguments in favour of the features of the organization and operation of insurance activities of small businesses. There is a need for the intensification of insurance activities. Practical implications. The study of scientific works and the practice of economic activity indicate that some of the theoretical provisions regarding the interpretation of the features of the organization and operation of insurance activities of small businesses are of a polemical character, and a number of important aspects of their organization, evaluation, and the methods of organization should be improved. Value/originality. The main directions of the insurance activity of small businesses in the global economy have been studied. The ways and directions of activation of insurance activities are offered. The strategy of the development of small and medium-sized businesses in the insurance sector in Ukraine is proposed. The strategy is aimed at ensuring the gradual development of insurance activities of small businesses, given the temporarily limited financial support and significant challenges in the economy of Eastern European countries.
\end{abstract}

Key words: insurance, insurer, insurance market, small business, entrepreneurship, state support.

JEL Classification: M21, E21, O12, R58, R13

\section{Introduction}

Recently, the problem of small business development is gaining global importance. It has become urgent even in developed countries. The small business performs a number of important economic and social tasks. In addition to tax payments to the budgets of all levels, it develops the real sector of the economy, creates additional jobs, and promotes competition. Therefore,

\footnotetext{
Corresponding author:

${ }^{1}$ Sumy National Agrarian University, Ukraine.

E-mail: 1.poliatykina@ukr.net

${ }^{2}$ Sumy National Agrarian University, Ukraine.

E-mail: ira_samoshkina@ukr.net

${ }^{3}$ Sumy National Agrarian University, Ukraine.

E-mail: olena.slavkova.snau@gmail.com
} 
the development of small business is an important task of the economy of Eastern Europe.

The sphere of small business is an important sector of economic development of the state, region, territorial community. Entrepreneurs assume the responsibility and risks of doing business and create tangible and intangible values that are the basis of the country's wellbeing, form a significant part of the tax revenues of the state and local budgets.

At present, entrepreneurial business requires strong government support. Both government authorities and public organizations of entrepreneurs themselves (unions, associations, agencies) should provide small business with every possible assistance. To do this, it is necessary to formulate a clear unified state and non-state policy regarding the development of small business, using the best practices of developed countries across the globe.

The modern economy is characterized by a complex combination of different scale of production: large scale with a tendency towards monopolistic structures, and small one emerging under the influence of many factors. On the one hand, the steady trend of scientific and technological progress is the concentration of production. It is the large firms with large material, financial, and human resources, qualified personnel that are able to make large-scale scientific and technical developments, which determine the technological progress. On the other hand, in recent years, there has been an unprecedented growth of small and mediumsized businesses, especially in areas where there is no need for significant capital, a large amount of equipment and cooperation of a great number of employees. There are a lot of small and medium-sized enterprises in knowledge-intensive industries, as well as industries related to the production of consumer goods and the provision of services.

In order for small businesses to be able to acquire an advantage over their large and medium-sized competitors, it is advisable for them to create various kinds of associations, both short-term and longterm. It should be mentioned that small businesses have vulnerabilities. The main one is a small amount of individual capital. For the vast majority of small enterprises, self-financing is the main source of seed capital or the replenishment of funds already invested in the business, and only in the case of sufficiently successful business operations, it is possible to use bank loans. But commercial banks are always reluctant to engage with small businesses because small loans are less profitable for them.

The differentiation and individualization of demand in the sphere of production and personal consumption contribute to small production. The development of small business production creates favourable conditions for putting the economy back on a sound footing, as it contributes to the development of the competitive environment, the creation of additional jobs, the implementation of structural reorganization, the expansion of consumer sector. In addition, the development of small business leads to saturation of the market with goods and services, an increase in export potential, more effective use of local raw materials.

\section{Development of insurance activity of small businesses in the countries of Eastern Europe}

The analysis of foreign experience enables to look at the prospects of small business development in a new way. In light of the current economic crisis, which has affected many states, the problem of small business has appeared ever more pressingly. As the best practice shows, the main criterion, on the basis of which enterprises of various organizational and legal forms belong to small business entities, is, first of all, the average number of employees per enterprise.

The degree of small business development directly characterizes the degree of development of the state economy as a whole. The development of small businesses in the countries of Eastern Europe is at an even greater rate, as national governments pay considerable attention to small businesses and contribute to their development at the national level. In most countries, small business is the middle class, which is the basis for sustainable economic development.

As the literature review shows, countries that are developing thanks to small and medium-sized business have made great economic progress (Taiwan, Singapore, Indonesia, etc.). If we observe how the pace of development of small enterprises in these countries has changed, we can draw a parallel between the development trends in the whole country.

For Europe, small business is a kind of basis for socio-economic development. There are more than 20 million enterprises engaged in small and mediumsized business and, accordingly, give more than half of the total turnover and value added. The share of employed in small business in Europe is about $70 \%$. The vast majority of small enterprises work in trade, construction, and food industry. It can be stated that small business stimulates manufacturers to compete. Their development depends on the success of the small and medium-sized business. Therefore, a policy of support for small business, the main goal of which is to balance the interests of the state and business, ensure the best conditions for entrepreneurial activity, increase the competitiveness of small business, is implemented within the framework of the European Union.

Analysing the development of small business in different countries, it is expedient to focus on Japan as a country of individual entrepreneurship. In this country, 5,738,000 enterprises, that is $99 \%$ of their total number, refer to small business. They employ $88 \%$ of all employees. 
In the USA, $77 \%$ of private sector employees work in small business, accounting for $47 \%$ of the total sales of goods in the country, as well as $50 \%$ of the gross domestic product. The Small Business Administration (SBA), which solves three important tasks (financial support to small and medium-sized enterprises, assistance in obtaining state orders, provision of technical and consulting services on management issues), is the leading body of state support for small business.

As for England, the government tries to support small business, primarily through the banking system. In particular, each bank has its own lending program. One of them is a program for creating and expanding the business that provides for the granting of credit in the amount of 5-100 thousand pounds for a period of 5 years.

In the EU countries, the share of the population working in insurance companies in 2017 was, on average, $0.45 \%$. Insurance density is of particular importance for the characteristics of insurance in small businesses.

Such countries as Sweden, Germany, Austria, Spain, Luxembourg, etc. are characterized by the high level of insurance penetration. The countries of Eastern Europe (Czech Republic, Poland, Hungary, Bulgaria, etc.) are characterized by the lowest rates of insurance penetration, not exceeding $3 \%$. The Ukrainian insurance market shows a significantly lower level of development not only in comparison with the most developed European countries but also in other countries of Eastern Europe. Among the main factors causing problems in the development of the insurance market, we can distinguish the following. First, the structure of insurance portfolios of many insurance companies is unsatisfactory. In particular, the low demand for insurance services leads to an increase in the volume of insurance activities mainly due to compulsory types of insurance.

\section{Features of the implementation of insurance activities}

The insurance market is characterized by its insufficient development, structure imperfection, a tendency towards the conclusion of short-term contracts, weak development of reinsurance, instability of the financial condition of plenty of insurance companies that results in untimely fulfilment of obligations to insurers.

The increase in the share of life insurance in the structure of the insurance market will contribute to the development and promotion of cumulative insurance in general, as well as the growth in the economic standard of living of the population, which will lead to an increase in savings. The increase in the level of insurance payments can be achieved by increasing the financial solvency of insurance companies, including by increasing their income from investment activities. The conditions for achieving this goal at the macro level is to stabilize the economy as a whole, the banking sector, and promote the development of the stock market; at the micro level to form a balanced structure of the insurance portfolio of insurance companies, to implement an effective marketing policy in relation to insurance services. The conducted analysis of the development of the insurance market of Ukraine in comparison with the European Union has shown that in terms of insurance density, the penetration of insurance and the level of insurance payments, Ukraine occupies the last and penultimate position among European countries. At the same time, the insurance market is negatively characterized not only by its significant lagging behind such developed countries as Germany, Sweden, Finland, France, and others but also by significantly weaker positions compared to the countries of Eastern Europe - Bulgaria, Hungary, Czech Republic, Poland, Slovakia. The main challenges of the development of the insurance market are: the formation of an unbalanced structure of the insurance portfolio of individual insurance companies and the resulting disproportions in the development of various types of insurance; low level of insurance payments and the problem of integrity of insurance companies; public distrust of insurance companies and low interest in insurance products; limited reliable and liquid financial instruments for the implementation of investment activities of insurance companies. All abovementioned problems and imbalances in the development of the insurance market are interrelated and require a comprehensive solution.

Features of the implementation of insurance activities in Ukraine. Despite the difficulties in the formation of the national insurance market, the volume of insurance operations is significantly increasing. This is due to the fact that in the non-market economic environment, the compensation for damage was mainly made by the state at the expense of budget in Ukraine. The implementation of the program of property privatization has intensified the need for insurance protection of new owners of property from the risks that lead to its loss or damage.

During the years of independence, Ukraine created mainly a legislative and regulatory framework for insurance. This has made it possible to develop the insurance market on the principles of competition that contribute to the improvement in the quality of insurance services. However, nowadays the level of the insurance market development in Ukraine is not more than $10 \%$ of potential risks, while this figure reaches $90-95 \%$ in most developed countries. The share of our country in the world market reaches only $0.01 \%$, and less than $0.05 \%$ of the volume of insurance services provided in Europe, despite the fact that Ukraine is home to more than 7\% of the European population and has a large industrial, agricultural, and scientific potential.

The development of the national insurance system over a three-year period is characterized by a significant increase in the following indicators. 
Given the level of inflation, there was an actual growth in the volume of the market of insurance services. It should be noted that the insurance market of Ukraine is much younger than the insurance markets of the leading countries of Europe (some of them have been operating for more than 100 years).

Insurance activities may be carried out with the involvement of insurance brokers and insurance agents as the excluded activity and may include consulting, expert information services, work related to the preparation, conclusion, and execution of insurance (reinsurance) contracts.

Insurance agents are considered to be citizens or a legal entity that acts for and on behalf of the insurer and performs a part of its activities (conclusion of insurance contracts, receipt of insurance payments, the performance of works related to the payment of the amount of coverage and insurance indemnity). The insurance agent is a representative of the insurer and acts in its interests for a commission on the basis of an agreement concluded with the insurer.

The set of insurers operating in a certain economic environment forms the insurance system. Its main task is to provide insurance services. The insurance market is characterized by the ongoing diversification of companies on a departmental basis - the creation of their own captive insurance companies in industries, departments, spheres of production, and even at individual enterprises.

A captive insurance company is a subsidiary company established by an industrial or commercial enterprise (a group of companies, financial group, etc.) in order to cover its own risks. The main purpose of the creation of captive insurance companies is to keep the funds allocated for insurance at the disposal and under the control of the founders of a parent company, which are the clients of their captive companies.

There are no limited liability companies in the list of permitted types of organizations in Ukraine. It is known that such business structures are very common in the family business. Owners in case of any danger are responsible for the debts of the company only to the extent of the contributions made to the authorized fund. The conditions for the establishment of these companies protect against the penetration of undesirable actors into their business. Along with the positive, there are plenty of negative factors, in particular, few opportunities to increase the authorized capital, difficulties in exercising control over the company operation that is especially important in the field of insurance services.

The state regulation in Ukraine is carried out on the basis of the two interrelated and, at the same time, most influential forms: legal support and supervision over insurance activities. The legal support of insurance is carried out through the adoption of legislative acts and regulations governing insurance activities. The task of the state body of insurance supervision is to protect the interests of policyholders and ensure the reliable operation of insurers in the insurance market. At present, the state supervision of Ukraine over insurance activities enables to prevent financial shortage that may occur if insurers fail to comply with the requirements of the insurance legislation. But it must be understood that Ukraine belongs to the emerging market countries, which are characterized by significant instability and a large number of business risks. Therefore, at this stage, taking into account the problems of non-payment in the economy, the critical financial condition of the majority of enterprises-insurers, low level of solvency of the population, as well as undermined public confidence in the financial system, it is expedient to consider an increase in the financial reliability and solvency of insurers to be the most priority activities of the insurance supervision bodies.

The effective supervision over insurance activities is one of the most important prerequisites for ensuring social and economic stability in the society, and the improvement of the efficiency of supervision bodies is one of the main tasks for the government of each country.

Foreign experience. Compared with European countries, Ukraine has the insurance market, which is at a significantly lower level of its development, characterized by insufficient capitalization and financial stability of insurance companies, unbalanced development of certain types of insurance, the low interest of the population in insurance services. However, the focus of Ukraine on European integration determines the need for a comparative analysis of the domestic and European insurance markets to identify and overcome the main shortcomings and imbalances of the domestic insurance market, to ensure its sustainability and competitiveness. Despite an increased focus of domestic scientists on the functioning of the insurance market, the level of its development remains extremely low, compared to European countries. It is necessary to analyse not only the main characteristics of the current state of the insurance market, regularity and shortcomings of its development, but also the relationship between the general economic and specific factors and indicators of the market development, the formation of a set of measures to improve its functioning.

\section{Prospects for the development of insurance in small businesses}

The main objectives of small businesses may include: innovative growth and development of industries, regions, and the country as a whole; rise in the standard of living of the population of regions and the country as a whole; the formation and sustainable progressive development of the innovative economy of the state. To achieve them, it is necessary to form and provide priority directions of innovative development of small businesses, as well as to develop a comprehensive model of socioeconomic operation of small businesses as one of the main elements of the innovative production mechanism. 
In connection with the goals to be sought, small business is intended to solve the following tasks: to identify the factors of innovative growth of large, small, and medium-sized businesses, as well as to determine the impact of each factor; to identify the factors affecting the improvement of the level and quality of life of the population; to characterize the possibility of expansion of the middle social layer, as well as to form the priority directions of innovative development of small business.

The development of the market will result in the transition of the insurance business to a commercial basis and an increase in the cost of services. However, there is another, a non-profit form of an insurance organization, which does not pursue the purpose of making a profit. This form is presented by mutual insurance companies.

Mutual insurance companies, like joint-stock insurance companies, insure property interests related to life, health, working capacity, and pension provision of the policyholder or insurer. The property interests, such as the risk of loss, shortage or damage to property; the risk of liability for damage to the life or property of other persons (civil liability) and the risk of losses from business activities due to the counterparty's failure to fulfil its obligations, are insured. Citizens and legal entities may insure these risks by joining mutual insurance companies and raising the required amount of funds. Members of the company are both policyholders and insurers that create the economic prerequisite for providing them with real insurance protection at minimum prices.

The non-profit orientation of mutual insurance excludes profit from the price of insurance, and the possible excess of insurance premiums over insurance payments and the investment income of the mutual insurance company ensure a reduction in the price of insurance. Mutual insurance makes no profit. Its objective is to cover the costs of management and insurance risk. If the operating year results in excess, it is either distributed among members of the company or counted against their premiums. It only makes sense that mutual insurance should be cheaper than joint-stock insurance.

Summarizing all the above, we can add that the state and insurance business are partners. Their partnership is based on the unity of fundamental strategic interest, which is to create a highly efficient economy and achieve a high level of well-being of people.

The material basis for the organization of mutual insurance is financial and economic that is the provision of insurance services at more attractive price terms than in commercial insurance. The expansion of activities and an increase in the number of insurance risks leads to the increased importance of the insurance factor for an enterprise, as insurance costs increase accordingly. The actual reduction of corresponding expenses is provided by the organization of mutual insurance. In addition, the need for mutual insurance is determined by a large number of risks that commercial insurers refuse to insure because of their loss or great responsibility. The demand for the policyholder is satisfied directly by the policyholders the organization of the mutual insurance company.

\section{Conclusions}

For a more effective operation of elements of the infrastructure of business support, it is essential to carry out the following actions: to adopt the regulatory legal acts regulating the creation and operation of elements of the business support infrastructure; to adapt the international experience of formation and effective operation to domestic realities; to create the system of state accreditation of institutions of the business support infrastructure, which will provide training and advisory services to small business; to increase the amount of financing for the development of the business support infrastructure network; in particular, by providing funds from the state and local budgets, providing premises and required equipment on preferential terms, methodological and information support; to provide the business support infrastructure facilities with highly qualified personnel, etc.

Given the international experience, the main directions of the development of insurance activities in the countries of Eastern Europe could include the following:

- development of life insurance due to the fact that this type of insurance plays an important role in ensuring the safety of citizens and the mobilization of capital;

- formation of legislation that stipulates for clear principles and regulatory procedures that meet the interests of both policyholders and insured parties;

- ensuring the regularity of reporting of insurers and intermediaries in a single form, taking into account the standards provided by the regulatory body;

- establishment of requirements for the minimum size of the authorized fund and requirements for the solvency of insurers;

- establishment of new rules for placement of insurance reserves;

- participation of foreign insurers in the market in order to provide the maximum range of insurance services; - the solution to the issue of compulsory health insurance of citizens, which is quite practiced in other countries;

- adoption of a long-term strategy for the insurance market development.

The ways and directions of improving the insurance market, in our opinion, will make it possible to accelerate the creation of a full-fledged insurance market as an objective attribute of the market economy and contribute to the restoration of trust of the policyholder from insurers. Given the trends in the global economy and the limited factors of production (land, capital, etc.), in the coming years, one should expect further growth in the production, processing, and provision of services to small businesses in the countries of Eastern Europe. 


\section{References:}

Database - Eurostat / European Commission. Retrieved from: http://ec.europa.eu/eurostat/data/database

Law of Ukraine "On Development and State Support of Small and Medium Enterprises in Ukraine" (2012) No. 4618-VI dated March 22, 2012. Retrieved from: http://zakon5.rada.gov.ua/laws/show/4618-17

Mikhailov, M. G., Poliatykina, L. I., \& Slavkova, O. P. (2008). Organization of accounting in small business enterprises. Kyiv: Center for Educational Literature.

Pakhnenko, O. M., Semenoh, A. Yu., \& Milyutina, M. O. (2017). Insurance market of Ukraine and EU countries: Comparative analysis. Monograph. Mukachevo.

Poliatykina, L. I. (2016). Methodological and accounting-analytical support of sustainable development of small business enterprises. Monograph. Sumy.

Poliatykina, L. I. (2018). Modern Trends to Promote Sustainable Development of Small Business Enterprises. Eurasian Academic Research Journal, Multilanguage Science Journal, 1(19), 138-142.

Poliatykin, L. I. (2018). Busines organization in the agricultural sector: Economic and law paradigm of modern society. Scientific Journal by Open Europe, 1, 44-49.

Poliatykin, S. O. (2018). Features of innovation and investment activity in foreign countries: Economic and law paradigm of modern society, Scientific Journal by Open Europe, 1, 39-44.

Statistical information. Retrieved from: http://ukrstat.gov.ua/

The Tax Code of Ukraine No. 2755-VI from 02.12.2010. Retrieved from: http://zakon5.rada.gov.ua/laws/ show/2755-17

Vasechko, L. I. (2016). Current issues of development of the insurance market of Ukraine. Economic Area, 109, 146-154.

Zhuravka, O. S. (2017). Analysis of the current state of the insurance market of Ukraine: Effective economics. Retrieved from: http://www.economy.nayka.com.ua/?op=1\&z=5493 